\title{
CONFLUENCIA ENTRE CULTURA NATIVA Y BLANCA EN EL TEATRO NATIVO-AMERICANO CONTEMPORÁNEO: GRANDMA Y GRANDPA (1984) DE HANAY GEIOGAMAH
}

\author{
Sidoní López Pérez, Universidad Internacional de La Rioja \\ E-mail: sidoni.lopez@unir.net
}

Recibido: 20 de Abril

Aceptado: 20 de Mayo

Resumen: Este artículo se centra en las obras teatrales, Grandma y Grandpa (1984) del dramaturgo nativo, Hanay Geiogamah, con la intención de reflejar cómo los personajes indígenas a menudo se encuentran en medio de una confrontación entre la cultura nativa y blanca que intentan reconciliar. Por una parte, es importante para ellos preservar sus tradiciones nativas y su identidad indígena; por otra parte, también ven necesario adaptarse a los cambios y costumbres de la sociedad moderna occidental, consiguiendo así una especie de conciliación entre ambas culturas que les permite asegurar su perpetuidad cultural y existencial a través del teatro nativo contemporáneo.

Palabras clave: teatro nativo, tradición nativa, cultura indígena, representación, sociedad occidental.

\begin{abstract}
This essays focuses on Grandma and Grandpa (1984), two theater plays by the Native playwright, Hanay Geiogamah, in order to reflect how indigenous characters often experience a confrontation between Native and white culture that they try to reconcile. On the one hand, it is important for them to preserve their Native traditions and identity; on the other hand, they are also aware of the necessity of adapting themselves to the changes and customs imposed by modern Western society, whilst achieving a union between the two cultures that allows them to ensure their cultural and existential survival through contemporary Native theater.
\end{abstract}

Keywords: native theater, native culture, indigenous culture, performance, western society. 


\section{INTRODUCCIÓN}

El drama indígena ${ }^{1}$ contemporáneo se desarrolló a partir del Renacimiento NativoAmericano, período de máximo esplendor de la literatura indígena que tuvo lugar a partir de 1968 con la publicación de la novela, House Made of Dawn, del escritor Kiowa, N. Scott Momaday. Influenciado por el resurgimiento cultural de la segunda mitad del siglo XX y marcado por el Movimiento de los Derechos Civiles, este género literario se presentaba como un excelente medio cultural y artístico que permitía conocer las culturas, tradiciones y costumbres indígenas desde una aproximación real y auténtica. Además, el teatro nativo contemporáneo alberga el carácter representativo de las culturas indígenas (procedente de las tradiciones orales o storytelling) y el carácter escrito (procedente de la civilización occidental). Por lo tanto, nos encontramos con un género literario que participa de ambas culturas, es decir, nativa y blanca, y es muy habitual encontrar a personajes indígenas en sus obras que viven a caballo entre la tradición nativa y la civilización occidental. Como veremos más adelante, en las obras teatrales, Grandma y Grandma (1984), los protagonistas nativos tratan de reconciliar la supervivencia de los valores culturales tradicionales indígenas con la adaptación o asimilación a las costumbres y tradiciones de la sociedad occidental.

\section{CONTEXTO HISTÓRICO Y LITERARIO DEL TEATRO NATIVO-AMERICANO}

El drama indígena con las características literarias actuales surgió a partir de la segunda mitad del siglo XX y tuvo lugar a través de la creación de distintas compañías teatrales nativas que impulsaron la publicación y producción de obras escritas por dramaturgos indígenas. Algunos críticos como Huntsman (2000: 95) sitúan la presencia de este género literario en los años 50, etapa que se corresponde con los primeros intentos por crear compañías teatrales. Asimismo, Geiogamah (2006: 1-2), dramaturgo nativo de origen Kiowa-Delaware, habla del comienzo del teatro nativo contemporáneo en los años $60 \mathrm{y}$ explica cómo los avances políticos, sociales y económicos de las minorías desde 1940 hasta 1960, propiciaron un gran impulso hacia la creación de esta nueva forma literaria teatral. Haugo (2013: 49) sitúa también la creación del teatro indígena contemporáneo hacia 1970 y habla del Movimiento del Teatro Nativo, correspondiéndose con la creación de las primeras compañías teatrales. Sin embargo, la escritora y dramaturga Cherokee, Diane Glancy, prefiere no centrarse en una fecha concreta y atribuye el inicio del drama nativo contemporáneo a la tradición oral indígena:

A los Indios no se les dan bien las fechas específicas. Quizás el teatro empezó en los pictogramas, pinturas antiguas en las cuevas que parecían moverse a la luz del fuego. El story-telling en la

1 En este artículo utilizaremos los términos "indio", "indígena" y "nativo" indistintamente para referirnos de forma general a los pueblos indígenas de los Estados Unidos. No obstante, siempre que sea posible incluiremos los nombres específicos de las tribus. 
tradición oral podría llamarse una forma temprana de teatro, una obra de un solo personaje. La acción o el argumento era la voz contando la historia que era sustancial para la supervivencia².

De acuerdo a Glancy (2007), es muy posible establecer un vínculo entre el "story-telling” tradicional y el teatro nativo, especialmente si tenemos en cuenta que las historias, leyendas, relatos, cuentos y mitos de las culturas indígenas no solo se contaban y transmitían de generación en generación, sino que además se representaban utilizando distintos elementos teatrales (López Pérez \& Benali Taouis 2016: 94). Además, varios dramaturgos nativos y críticos de este género literario coinciden en que la narración de historias de carácter oral o "story-telling" es una parte central y muy importante en las obras de teatro indígenas (véase Pulitano 1998; King 2000; Spiderwoman Theater and Coatlicue Theater Company (citados en Haugo, 2000); Taylor 2007³; Schäfer 2013). Por lo tanto, las similitudes entre la narración de historias y el teatro nativo contemporáneo se pueden apreciar fácilmente y todo parece indicar que "los comienzos del teatro nativo contemporáneo deben mucho más a esta tradición [story-telling] que a rituales o ceremonias elaborados" ". No obstante, esta es una cuestión que todavía continúa siendo objeto de debate, puesto que varios dramaturgos indígenas y críticos opinan también que el teatro nativo proviene de rituales y ceremonias (véase Wilmeth and Miller 1996; Huntsman 2000; Geiogamah 2011).

Por otra parte, este género literario ha tenido una larga historia de opresión, discriminación, silencio y desplazamiento (Däwes 2007; López Pérez \& Benali Taouis 2016). Esto se debe principalmente a distintos factores como, por ejemplo, la ausencia del teatro como género literario dentro del canon literario de Estados Unidos, la herencia de la tradición puritana en los siglos XVI y XVII, la discriminación del teatro nativo frente al teatro occidental y los efectos del colonialismo (Däwes 2007; López Pérez \& Benali Taouis 2016). Sin embargo, actualmente el drama nativo contemporáneo cuenta con numerosas obras de teatro y una considerable crítica literaria que además de reflejar el interés generado por este género literario, también demuestran “cómo el drama indígena americano ha pasado de comunidades específicas y culturales a audiencias más grandes y generalizadas"5. Aun así, el panorama teatral nativo en los Estados Unidos continúa teniendo algunos problemas, entre los que destacamos la insuficiente financiación procedente tanto del gobierno federal y local como de fundaciones y tribus (Geiogamah 2013: 330). No obstante, el drama nativo contemporáneo sigue abriéndose camino a través de su larga lista de obras teatrales y una considerable crítica literaria que últimamente se dirige no solo a establecer importantes vínculos culturales, históricos y literarios con el teatro indígena canadiense, sino también

2 Indians don't do well with specific dates. Maybe theatre began in pictographs, old cave drawings that seemed to move in the firelight. Story-telling in the oral tradition could be called an early form of theatre, a one-character play. The action of plot was the voice telling the story that was integral for survival (comunicación personal, 20 de septiembre de 2007: 3).

3 Taylor, D. H. 2007. Comunicación personal, 8 de agosto de 2007.

4 " $[\ldots]$ the beginnings of contemporary Native theatre owe a lot more to this tradition than to elaborate rituals or ceremonies" (Schäfer 2013: 30).

5 “ $[\ldots]$ how American Indian drama has moved from specific and cultural communities into larger and more generalized audiences” (López Pérez \& Benali Taouis 2016: 107).

Odisea, $\mathrm{n}^{\circ}$ 20, ISSN 1578-3820, 2019, 93-104 
con otras culturas indígenas en el mundo (véase Däwes 2013; Däwes \& Maufort 2014; Morgan, Hornung \& Tatsumi 2019). Además, este género literario continúa expandiéndose, dando asimismo lugar a nuevos temas y formas de expresión (López Pérez \& Benali Taouis, 2016: 108).

\section{GRANDMA Y GRANDPA (1984): CONFLUENCIA ENTRE TRADICIÓN NATIVA Y CULTURA BLANCA}

Hanay Geiogamah es el primer dramaturgo nativo-americano que publicó una colección de obras teatrales y uno de los dramaturgos más prolíficos del teatro nativo contemporáneo (Pinazzi 2000: 175). En 1984, la compañía teatral, Native American Theater Ensemble (NATE), fundada por Geiogamah y Ellen Stewart, produjo Grandma y Grandpa, dos obras de teatro de este dramaturgo indígena que contienen un solo acto y que transcurren a través de un monólogo escenificado por cada uno de sus protagonistas. Aunque son dos obras, en realidad se trata de piezas complementarias y, como veremos, poseen muchos aspectos en común. Al igual que sucede en la gran mayoría de obras teatrales nativas, en Grandma y Grandpa los protagonistas deben tratar de reconciliar la supervivencia de los valores culturales tradicionales indígenas con la adaptación o asimilación a las costumbres y tradiciones de la sociedad occidental, puesto que a menudo aparece una confrontación entre cultura nativa y blanca que no siempre es fácil de reconciliar.

La primera de estas obras teatrales, Grandma, transcurre en torno a un largo monólogo pronunciado y escenificado por una anciana indígena tradicional, "Ella". Al comienzo de la obra, después de recitar un breve discurso (Grandma: 318), la protagonista se presenta a sí misma, dirigiéndose y haciendo partícipe a la audiencia y desvelando al mismo tiempo la afinidad entre actor y público. La anciana relata una historia que forma parte de la comunidad indígena y muestra el concepto de unidad de la comunidad tribal. En todo momento teatro y público se encuentran al mismo nivel y ambos son partícipes de los acontecimientos.

La protagonista manifiesta su alegría por la ceremonia de nombramiento de su nieto, una celebración tradicional muy característica de las culturas nativas que no se había vuelto a realizar desde la muerte de su marido. "Ella" parece estar preocupada por la pérdida de dicha tradición y advierte acerca de la posibilidad de asimilación hacia la cultura blanca: "Este es el primer nombramiento en nuestra familia desde hace años. Después de la muerte de mi marido, fue difícil mantener unida a la familia y conservar las tradiciones. Siempre les insisto, les digo que van a empezar a comportarse como esos viejos tontorrones de la televisión si no preservan algunas de nuestras tradiciones"6. Sus palabras parecen indicar que los ancianos continúan siendo los transmisores de la cultura nativa, así como los unificadores de la familia y comunidad tribal.

La anciana "Ella" es una figura claramente representativa de los valores culturales nativos. La protagonista es la encargada de recitar un discurso y decir unas palabras en la

6 Original text: "This is the first name-giving our family's had in, oh, few years now. After my husband passed away, it kinda got harder to get everyone in the family to hold things, keep up our family ways. I always get after all of them, tell them they're gonna start acting like those old goofy television people if they don't keep up some of our ways" (Grandma: 319). 
ceremonia de nombramiento de su nieto a la cual asisten miembros de distintas tribus vecinas que "Ella" ha invitado para recibir y acoger al nuevo miembro de la familia. Además, a lo largo de la obra podemos apreciar cómo la anciana indígena cuenta historias, no solo a la audiencia, sino a sus nietos para así continuar con la preservación de los valores culturales nativos. Esta es una función tradicionalmente asignada a las mujeres indígenas, pues la identidad nativa proviene del concepto madre-tierra, en donde la tierra es la madre de todos los indios (Allen 1992: 119).

Sin embargo, no podemos decir que en todas las obras teatrales sea siempre una mujer la persona encargada de la transmisión de los valores culturales indígenas. En Grandpa, encontramos a un anciano nativo con gran sentido del humor que sigue siendo fiel a ciertas tradiciones indígenas e incluso invita a la audiencia a participar en ellas. El anciano "Guy" todavía continúa arraigado en algunas costumbres nativas que ha conseguido transmitir tanto a sus hijos como a sus nietos. Así, podemos comprobar que el género masculino también contribuye a la transmisión de dichos valores, pues aunque esta es una tarea tradicionalmente asociada a las mujeres en las culturas nativas, está claro que los ancianos (sean hombres o mujeres) tienen una función primordial como transmisores de dichas culturas y de distintos conocimientos, que pueden ayudar a las nuevas generaciones a construir un futuro saludable (Kahn et al., 2016: 117; Pinazzi 2000: 189).

Aparte de la fuerte intención de transmisión cultural que aparece en los personajes indígenas de las obras teatrales nativas, la presencia de la sociedad norteamericana no deja de influir en la incierta perpetuidad cultural y existencial de los indios. En Grandma, la protagonista afirma estar molesta por las falsas imágenes hacia los indígenas y la política desfavorecedora del gobierno norteamericano. "Ella" alude particularmente al escaso conocimiento del hombre blanco sobre la cultura indígena y a la identidad colectiva asignada a los indios desde la llegada de Cristóbal Colón:

ELLA. Cuando estuve en el hospital de Darko hace un par de años, para arreglar mi pie, me cuidaba una joven enfermera. Era una chica agradable y simpática. Me compró un ramo de flores. Dijo que también era la enfermera de otros colegas indios y que le caían bien todos. Le pregunté a qué tribus pertenecían, si yo les conocía. Me miró graciosamente y dijo, 'No. Sólo eran indios"7.

Sus palabras son muy evidentes, puesto que demuestran la perpetuidad de las falsas imágenes de los indígenas a través de la historia, mostrando así una cierta ignorancia y desinterés que todavía existe en torno a las culturas nativas. "Ella" se siente indignada ante la falta de conocimiento de la sociedad blanca con respecto a las distintas tribus indígenas: “[...] la mayoría de la gente blanca de aquí probablemente no sabe la diferencia entre una tribu y otra. Os apuesto que podríais preguntarle a un chico blanco en la gasolinera si sabe

7 ELLA. When I was in Darko hospital couple of years back, to get my food fixed up, young nurse girl was takin' care of me. She was nice, and friendly. She bought me a bunch of flowers. She said she was nurse for few other Indian folks in there too, and she liked all of them. I asked her what tribes they were from, if I knew some of them. She looked at me funny and said, 'No. They were just Indians' (Grandma: 321). 


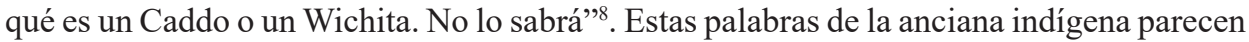
indicar que el interés del ciudadano americano hacia los indios sigue siendo de carácter bastante limitado y generalizado, pero también nos parece que las palabras de la protagonista reflejan la desunión entre los propios indios, quitándoles fuerza en sus reivindicaciones.

Por otra parte, la anciana manifiesta su descontento con la agenda de la Oficina de Asuntos Indígenas (BIA), pues parece ser que los indios no están recibiendo gran ayuda de este organismo. Como consecuencia, "Ella" confiesa claramente al público que le gustaría llevar a cabo alguna manifestación para clausurar esta institución (Grandma: 321), reivindicando así la lucha por el activismo político y social que había dominado la segunda mitad del siglo XX. Además, a lo largo de la obra, "Ella" se dirige al público para incitar a las comunidades tribales a no tener miedo, a unir sus fuerzas y luchar para conseguir que las injusticias en contra de la cultura e identidad indígena dejen de existir, demostrando así la habilidad de Geiogamah para representar a los indios de una forma muy natural a través de la acción (Vassar 2007: 134).

Esta situación nos recuerda nuevamente a una de las escenas de la obra teatral Grandpa, en la que el anciano "Guy" inicia un diálogo con la audiencia para hablarle de la pérdida de sus gafas y algunos aspectos de su vida. El protagonista confiesa que necesita sus anteojos para observar a las mujeres, aunque para ello debe ser muy cuidadoso e incluso muestra a la audiencia la forma en la cual debe mirar para pasar desapercibido (Grandpa: 335). La escena no dejar de ser cómica y refleja claramente la importancia y utilización del humor en las culturas y literaturas indígenas, puesto que como indica Lincoln (1993: 22-23), el humor actúa como una especie de "pegamento étnico" y sirve para subvertir el poder del colonialismo. En este caso, también podemos observar cómo "Guy" hace referencia a los efectos del colonialismo cuando cuenta que debe usar las gafas para acudir al centro tribal y recoger los enseres que le pertenecen, advirtiendo que puede ser engañado fácilmente (Grandpa: 335). Este hecho pone de manifiesto que los indígenas todavía se encuentran en una situación bastante discriminatoria, ya que siguen siendo víctimas de abusos. Por lo tanto, a través de las denuncias que realizan los personajes indios en esta obra, podemos observar nuevamente el conflicto entre cultura indígena y blanca que acorrala a las comunidades tribales.

Volviendo de nuevo a la obra teatral Grandma, debemos resaltar que "Ella" sigue la misma línea de denuncias y abusos con respecto a su cultura nativa. La protagonista expresa su incómoda inconformidad con los criterios de definición de identidad pronunciados por el gobierno estadounidense. Además, "Ella" aprovecha también para denunciar la propia pasividad de los indios frente a esta situación que ha originado tanta polémica: "Quieren elaborar nuevas formas para decir quién es indio y quién no - de todos nosotros, de cada uno. Y quieren utilizarlas para decir por qué eres indio. ¡Oooooh! Pobres amigos indios. Somos pobres, porque les permitimos hacer este tipo de cosas. Deberíamos haberles echado ya hace tiempo".

8 “[...] most of the white folks 'round here probably don't even know the difference between one tribe and another one. I bet you could ask white boy at filling station if he knows what's a Caddo, or a Wichita. He won't know" (Grandma: 321).

9 “They want to work out new way of telling who's Indian and who's not - all of us, every one. And they want to kind of work it out to tell why you're an Indian. Oooooh! Poor old Indian folks. We're poor things, 'cause we let them do all this kind of bad stuff to us. We shoulda run 'em off a long time ago" (Grandma: 329). 
"Ella" está incitando nuevamente al pueblo indígena a tomar la iniciativa y reivindicar una voz tribal propia. Además, esta también es una forma de demostrar que la lucha por el activismo político no es solamente un aspecto destacado del período de resurgimiento del orgullo étnico de la segunda mitad del siglo XX, sino que también aparece reflejado en el teatro nativo contemporáneo. No obstante, nos parece necesario puntualizar que el activismo político no es un aspecto muy común en las obras teatrales indígenas y aunque no queremos decir que la pugna política de los indígenas no sea importante para las comunidades tribales, se puede apreciar que los dramaturgos nativos están más interesados en la lucha por la supervivencia cultural e identidad nativa, que en cuestiones meramente políticas. Además, esta actitud pone de manifiesto la perspectiva de Geiogamah (citado en Pinazzi 2000: 189), quien ha comentado claramente que nunca quiso ser un defensor del odio hacia los blancos, ni tampoco hacia al gobierno y que los indígenas han perdido mucho tiempo odiando a los blancos.

Otro aspecto que nos permite apreciar claramente la confrontación entre mundo nativo y blanco es la propia experiencia sufrida por los indios en las escuelas en régimen de internado. En Grandma, "Ella" relata las dificultades que tenía para aprender inglés, mientras seguía aferrada a su idioma nativo: "La profesora nos decía cómo hacer eso del pasado y presente, y yo seguía hablando siempre en pasado. Le decía a la profesora, 'yo hablaba Kiowa'. Y ella me contestaba, ‘ ¡No, no! Tienes que decir, 'hablaba Kiowa antes de venir aquí, y ahora hablo inglés" "10. Las palabras de "Ella" están haciendo referencia al obligado aprendizaje de la lengua inglesa impuesta por la sociedad blanca. Este fue un proceso en el que los distintos idiomas nativos debían ser olvidados, ignorados y reemplazados, pues estos simbolizaban las culturas indígenas, su pasado y carácter primitivo. Por el contrario, la lengua inglesa representaba la civilización blanca, el presente y futuro, abriendo las puertas hacia la sociedad norteamericana. Sin embargo, "Ella" continuaba hablando en pasado, mostrando así la importancia de este tiempo verbal para los indios.

En las culturas indígenas el pasado forma parte del presente y el futuro, y el tiempo no se sucede de forma cronológica ni lineal, sino que se concibe de forma circular (Deloria 1994; Fixico 2003), esto es, pasado, presente y futuro están intrínsecamente relacionados. Por eso "Ella" continúa utilizando su lengua nativa, es decir, para no olvidar las tradiciones indígenas que forman parte del pasado de su herencia cultural. A su vez, consigue mantenerlas vivas para que formen parte de su presente y futuro, abogando así por la perpetuidad cultural y existencial nativa. Este concepto de circularidad del tiempo proviene además del concepto de unicidad del universo indígena donde todo está relacionado entre sí. Como afirma Fixico (2003: 1), “el ‘Pensamiento Indio’ es ‘ver’ las cosas desde una perspectiva que enfatiza que los círculos y los ciclos son centrales al mundo y que todas las cosas están relacionadas dentro del universo" $"$.

10 "Teacher was telling us how to do that past tense and present tense thing, and I kept putting everything in the past one. I'd tell her, 'I spoke-ded Kiowa'. And she would say back, 'No! No! You say, 'I spoke Kiowa before I came here, and I speak English now' (Grandma: 321-22).

11 "'IndianThinking' is 'seeing' things from a perspective emphasizing that circles and cycles are central to world and that all things are related within the Universe". 
Hacia el final de la obra, asistimos a la ceremonia nativa de nombramiento del nieto de "Ella". La protagonista agradece la participación a toda la comunidad tribal y pide su ayuda para educar y enseñar al pequeño los valores culturales tradicionales. Asimismo, "Ella" invita a la audiencia a la celebración de dicho evento cultural, demostrando así la importancia del teatro como elemento colectivo. Además, ella misma cuenta que dará un discurso utilizando su lengua nativa, pues así consigue reafirmar todavía más la importancia del pasado tradicional indígena: "Voy a dar un pequeño discurso en el idioma de la tribu allí esta noche. Siempre hablo en el idioma de la tribu en actos como este. Actualmente solo la mayoría de los ancianos lo sabemos. Pero algunos de los jóvenes están aprendiendo"12. La utilización de la lengua nativa constituye una especie de vínculo fuerte y positivo con las culturas indígenas que, como apunta Wexler (2009: 267), puede ayudar a la gente joven no solo a entender la historia, tradiciones y costumbres de sus tribus, sino también a enfrentarse y soportar ciertas dificultades que puedan encontrar a lo largo de su vida. Por lo tanto, creemos que a través del nieto de "Ella" tendrá lugar una conciliación entre la supervivencia de los valores culturales nativos y la asimilación occidental. La anciana indígena pide a los miembros de la comunidad tribal que ayuden a su nieto, tanto para conocer la historia y cultura nativa, como para vivir feliz en el presente y prepararse para el futuro (Grandma: 330).

Por una parte, "Ella" se apoya en el sentido de unión de la comunidad tribal para contribuir a la inculcación e integración de su nieto en la tradición nativa, pero también es consciente de que el crecimiento y educación del niño en el seno de la sociedad blanca mayoritaria impulsará su adaptación a los nuevos cambios. Esto nos lleva a deducir que este bebé podría unir o reconciliar la cultura indígena (tradición) con la civilización blanca (modernidad), dando lugar a una especie de síntesis entre ambas culturas. Además, también es posible observar cómo "Ella" ha conseguido esa reconciliación por sí misma, puesto que nos encontramos con una protagonista que no vive retenida en el pasado indígena, es decir, aunque su identidad es claramente nativa, "Ella" también es consciente de los cambios de la sociedad moderna y se muestra bastante receptiva a estos. La anciana cuenta historias a sus nietos para transmitir la tradición oral y lograr que conozcan el pasado indígena. Sin embargo, al mismo tiempo "Ella" reconoce las duras condiciones en las que vivían y parece sentirse más cómoda con los nuevos adelantos occidentales:

ELLA. Le enseñé este pequeño tallado a Clarice. Es mi nieta mayor. Le estaba hablando sobre su abuelo. Cuando le dije que vivía en un tipi cuando nació, madre mía, simplemente me miró y dijo, ‘Abuela. ¿Un tipi? ¿Un tipi de verdad?’ Eran tipis bastante grandes, la verdad. Tenían dos. Vivían allí en invierno y verano, con lluvia y tormenta. No había luz, ni agua, ni estufa para cocinar. Y no había 'O'. Quiere decir baño. Chico, me pregunto ¿qué pasaría si volviéramos a los viejos tiempos y tuviéramos que vivir con esas viejas costumbres?” Sí, sin Oes ${ }^{13}$.

12 "I'm going to give a little kind of speech in tribe's language over there tonight. I always talk tribe's language at doings like this. Mostly just us old folks know it now. But some of the young ones are learning" (Grandma: 321).

13 ELLA. I showed this little carving to Clarice. She's my oldest granddaughter. I was telling her about her grandpa. When I told her he was living in tipi when he was born, kaw-nay, she just looked at me and said, 'Grandma. A tipi? A real tipi?' They was pretty big tipis, though. They had two of them. Lived in there winter and summer, raining and storming. No electric, no water pipes, no cooking stove. And no ' $\mathrm{O}$ '. That's a toilet. Boy, I wonder what'd happen to us if we all got put back there to those old days and had to live by those real old ways? Geyall, no Os! (Grandma: 320). 
Su forma de expresarse parece indicar que "Ella" reconoce las ventajas que ha traído la civilización blanca con respecto a los viejos tiempos. Además, también parece percatarse de las mejores condiciones e incluso un próspero futuro que puede ofrecer la sociedad occidental a los indios:

ELLA. Ya saben, quiero que mis nietos piensen que pueden ser constructores, que pueden construir edificios, y empezar nuevos negocios y obtener títulos académicos altos - y ser listos como todos los demás piensan que son. Nuestra tribu podría hacer cosas mejores para sí misma. Todos ellos pudieron. Todo es difícil pero siempre fue difícil, mientras he estado aquí siempre lo ha sido. ¡Duro! Sí ${ }^{14}$.

Como podemos comprobar, la mentalidad de "Ella" responde también a una indígena progresista, pues aunque conserva su identidad y valores como nativa, posee además un gran anhelo de superación y mejora para los indios: "Demonios, deberíamos empezar a hacer planes para mandar a los indios a la luna y a esos lugares incluso más lejanos. Probablemente a la gente le gustaría ver a los indios allí fuera. ¡Ja! Iría, si me dejaran. Solamente montadme en ese gran cohete. Sí"15. Las palabras de "Ella" indican que no vive anclada en el pasado, sino que busca una proyección de futuro para el pueblo indígena mediante las posibilidades que le está brindando la supremacía occidental. En este sentido, la protagonista ha conseguido una especie de equilibrio entre la tradición nativa y la modernidad blanca, ya que como afirma Glancy (2007: 2), “el arte nativo también intenta llegar a la modernidad, que es un equilibrio entre el mundo antiguo y el nuevo. Un caminar entre los dos mundos porque es necesario hacerlo así. Este mundo lo demanda"16.

Además, la anciana utiliza también la lengua inglesa para hablar con sus nietos, aspecto que indica la unión o puente entre la tradición indígena y los jóvenes del presente. "Ella" cuenta historias a sus nietos en inglés para transmitir los valores culturales y tradiciones indígenas, es decir, la anciana nativa está claramente utilizando las comodidades y ventajas occidentales para asegurar la supervivencia existencial y cultural del pueblo indígena. Este aspecto reafirma las palabras de la dramaturga nativa, Monique Mojica (Kuna/Rappahannock) (1991: 3), quien afirma que los indígenas están reclamando el poder de la palabra, ya sea utilizando las lenguas indígenas o el idioma de la colonización para transformarlo en un lenguaje teatral nuevo y poder tomar prestadas las técnicas y herramientas del teatro europeo para crear un arte propio. Por lo tanto, podemos apreciar una especie de síntesis entre teatro nativo y europeo, o lo que es lo mismo, entre tradición (nativismo) y modernidad (eurocentrismo). El drama indígena contemporáneo en los

14 ELLA. You know, I want my grandkids to think that they can be builders, that they can put up buildings, and start up new businesses, and get high degrees - and be smart like everybody else thinks they are. Our tribe could do a lot better for itself. All of 'em could. Everything's hard, but it always was hard, long as I've been around here it has been. Hard! Aye (Grandma: 323).

15 "Heck, we oughta start planning on sending Indians out to the moon, and to those places even farther on out. They'd probably like Indians pretty good out there. Hah! I'd go, if they let me. Just put me on that big rocket. Aye" (Grandma: 323).

16 "Native art tries its hand at modernity also, which is a balance between the old world and the new. A walking-in-two worlds because it is necessary to do so. This world demands it" (comunicación personal, 20 de septiembre de 2007). 
Estados Unidos trata de moldear y adaptar el idioma anglosajón a la cultura indígena para crear una expresión literaria propiamente nativa, asegurando así la perpetuación cultural y existencial indígena. Esta combinación de elementos tradicionales y contemporáneos a través del teatro nativo resume claramente la posición del indígena, McGillivary (citado en Wheeler 1991: 11), quien afirma que debe haber un equilibrio entre el mundo antiguo y el mundo nuevo y que además "no es realista ser totalmente tradicional y no podemos ser totalmente contemporáneos porque perdemos nuestra identidad como pueblos"17. Este es un aspecto que hace del teatro nativo una forma literaria de creación exclusivamente indígena, puesto que participa de las características del mundo nativo (tradición) y civilización blanca (modernidad), reconciliando así eurocentrismo y nativismo.

Por otra parte, este comportamiento tan receptivo y, en cierta forma, ambivalente hacia la civilización blanca también es compartido por el anciano "Guy” en Grandpa. En primer lugar, las gafas que utiliza nuestro protagonista son un claro símbolo del presente y de las comodidades que ofrece la sociedad occidental:

GUY. Una vez, cuando estaba buscando esas gafas, pensé para mí mismo cómo podría haber visto si viviera mucho tiempo, muy atrás, cuando nadie tenía gafas.

Me pregunto ¿cómo esos viejos indios, veían las cosas, y cómo andaban por ahí y conseguían las cosas? Quizás no necesitaran ningunas gafas. Nunca le pregunté ni a mi padre ni a mi abuelo ni a ninguno de ellos sobre eso. Bah, creo que simplemente se las arreglaban bien ${ }^{18}$.

Al igual que "Ella", "Guy" parece encontrarse a gusto con el bienestar occidental. El anciano ve claramente ciertas ventajas y adelantos en comparación a las precarias condiciones de vida del pasado y sabe aprovecharlas. Sin embargo, "Guy" no ha perdido tampoco su identidad nativa ni los valores culturales como indígena, pues a lo largo de la obra podemos apreciar cómo el anciano disfruta tocando el tambor, además de cantar e incluso bailar alguna canción que pertenece a la tradicional Danza Redonda (Round Dance) y la Danza de la Guerra (War Dance). Los orígenes de la Danza Redonda se remontan a las danzas curativas de los Indios de las Llanuras y solían celebrarse durante los meses más fríos del otoño e invierno, siendo una ocasión excepcional para que los miembros de la comunidad tribal pudiesen reunirse, socializar y honrar sus culturas nativas. Actualmente sigue siendo un tipo de danza que se celebra en los "powwows" indígenas, con lo cual podemos apreciar que es una tradición indígena que ha conseguido perdurar a través del tiempo.

Además, en este caso podemos observar cómo "Guy" ha conseguido transmitir esa tradición a los miembros de su familia, puesto que afirma que tanto sus hijos como sus nietos comparten dicha tradición (Grandpa: 336). Aparte de continuar con la transmisión de los valores culturales nativos en la familia, el protagonista indígena también invita a la

17 'It's not realistic to be totally traditional and we can't be totally contemporary because we lose our identity as people (citado en Wheeler 1991: 11).

18 GUY. One time, when I was looking around for those glasses, I thought to myself how would I have been seeing if I lived long time ago, way far back, when nobody had eyeglasses. I wonder how those old Indians saw things, and how they got around and things? Maybe they didn't need any glasses. I never asked my daddy or my grandpa or any of them about it. Buh, I guess they just made out okay (Grandpa: 337 ). 
audiencia a ver y participar en estas tradiciones, puesto que además toca el tambor, canta y baila delante del público (Grandpa: 336). Además, agradece que le hayan ayudado en la búsqueda de sus gafas: "Sois todos muy buena gente. Venid cuando queráis, cuando queráis. Soy Guy, el Abuelo Guy. Sí. Quizás os vuelva a ver a todos"19.

Sus palabras reflejan nuevamente la importancia del teatro como elemento colectivo, pero también demuestran el gran sentido de unión de las comunidades tribales que parece estar abierto y extensible a personas con distintos orígenes étnicos y raciales. Como afirma Däwes (2007: 202), “independientemente de las afiliaciones biológicas, étnicas, religiosas o sociales de los espectadores, la obra aquí establece una comunidad grande y diversa, uniendo a la gente en el evento teatral de una conversación amistosa"20. Por otra parte, las gafas de "Guy" podrían interpretarse como un puente o unión entre la tradición indígena y la modernidad blanca, es decir, estaríamos hablando de las gafas como un elemento de síntesis o unión que reconcilia una vez más la supervivencia de los valores culturales indígenas con la asimilación occidental.

Así, podemos percibir que ambos protagonistas, "Ella" y "Guy", han conseguido llegar a una especie de reconciliación entre la cultura nativa y blanca. De la cultura indígena han sabido preservar la tradición oral a través de historias, relatos, discursos, ceremonias, canciones y bailes que han transmitido de generación en generación, mientras que de la civilización occidental han logrado acoger o asimilar la lengua inglesa, una esperanzada proyección de futuro, un gran encuentro multicultural y algunas ventajas y comodidades que les permiten vivir mejor en el presente y adaptarse a los nuevos cambios de la sociedad moderna. Por lo tanto, a través de estas obras teatrales podemos observar una especie de evolución del teatro nativo que, como afirma Glancy (2007: 2), "comienza con el viejo mundo, que entra en conflicto con el nuevo, y busca una curación o un puente entre las polaridades ${ }^{21} "$.

\section{CONCLUSIONES}

Aunque el teatro nativo contemporáneo surgió en la segunda mitad del siglo XX, es un género literario que cuenta con un gran número de obras teatrales en las que podemos apreciar cómo muchos personajes indígenas viven a caballo entre la tradición nativa y la sociedad moderna, donde las costumbres y tradiciones occidentales se hacen cada vez más fuertes. Sin embargo, también es muy importante para ellos preservar las tradiciones y la herencia cultural nativa, puesto que de ahí proviene su identidad e historia. Por lo tanto, son muchos los personajes indígenas que luchan para conservar estas tradiciones mientras se adaptan a los cambios que impone la sociedad contemporánea, consiguiendo así una especie de supervivencia cultural a través de este género literario.

19 "Y'all are really nice peoples. Y'all come over any time, any time. I'm Guy, Grandpa Guy. Aye. Maybe I'll see y'all again" (Grandpa: 338).

20 "Regardless of the spectators' biological, ethnic, religious, or social affiliations, the play here establishes a large and diverse community, uniting people in the theatrical event of a friendly conversation".

21 "It begins with the old world, which conflicts with the new, and looks for a healing or a bridge between the polarities" (comunicación personal, 20 de septiembre de 2007).

Odisea, $\mathrm{n}^{\mathrm{o}}$ 20, ISSN 1578-3820, 2019, 101-104 
En Grandma y Grandpa (1984) de Hanay Geiogamah, nos encontramos con unos protagonistas nativos que siguen fieles a la tradición nativa y continúan preservándola, pero al mismo tiempo son conscientes de los cambios que ha traído la sociedad occidental y que deben adaptarse a los mismos no solo para vivir en el presente, sino también para asegurar su perpetuidad cultural y existencial en el futuro. En realidad, es como si estos personajes indígenas caminaran o tuvieran un pie en cada mundo o cultura, pero siempre conservando su identidad como nativos. Por lo tanto, podemos apreciar en estos personajes una especie de síntesis desarrollada a través de una evolución natural sin renuncia a la propia identidad. Los elementos externos (cultura blanca) hacen evolucionar esa identidad desde ella misma y con sus propias respuestas. De esta forma, la síntesis no es ningún aglomerado desde el exterior, sino que se constituye claramente como un proceso interno.

Esta especie de síntesis o confluencia entre ambas culturas a la que llegan nuestros protagonistas, también puede apreciarse a través del teatro nativo contemporáneo. Este género literario contiene elementos muy tradicionales y característicos de las culturas indígenas, pero también posee elementos de la cultura occidental, es decir, las obras teatrales nativas contienen simultáneamente un gran carácter oral y de representación, que proviene de las culturas y tradiciones nativas, y un carácter escrito, esto es, narración, que proviene de la cultura blanca occidental (López Pérez 2019: 186). Por lo tanto, nos encontramos con un género literario que forma simultáneamente parte de la tradición nativa y de la civilización blanca, albergando y simbolizando en sí mismo un gran punto de confluencia entre ambas culturas que también se refleja en muchos personajes indígenas de las obras teatrales nativas.

\section{REFERENCIAS}

Allen, P. G. 1992. The Sacred Hoop: Recovering the Feminine in American Indian Traditions: with a New Preface. Boston, Massachusetts: Beacon Press.

Dëwes, B. 2007. Native North American Theater in a Global Age: Sites of Identity Construction and Transdifference. Heidelberg: Winter.

DäwEs, B. (ED.). 2013. Indigenous North American Drama: A Multivocal History. Albany: State University of New York.

Däwes, B. And Marc M., (Eds.). 2014. Enacting Nature: Ecocritical Perspectives on Indigenous Performance. Brussels: Peter Lang.

Deloria, V. 1994. God is Red: A Native View of Religion: The Classic Work Updated. Golden, Colorado: Fulcrum Publishing.

Fixico, D. L. 2003. The American Indian Mind in a Linear World. New York: Routledge.

Geiogamah, H. 1999. "Grandma”. Stories of Our Way: An Anthology of American Indian Plays. Ed. H. Geiogamah and J. T. Darby. Los Angeles: UCLAAmerican Indian Studies Center. 315-331.

Geiogamah, H. 1999. “Grandpa”. Stories of Our Way: An Anthology of American Indian Plays. Ed. H. Geiogamah and J. T. Darby. Los Angeles: UCLAAmerican Indian Studies Center. 333-38. 
Geiogamah, H. 2006. "Project HOOP: Advancing Critical Conversation and Scholarship in Native Theater and Performing Arts". Unpublished manuscript. Microsoft Word file.

Geiogamah, H. 2011. Ceremony, Spirituality and Ritual in Native American Performance: A Creative Notebook. Los Angeles: UCLA American Indian Studies Center.

Geiogamah, H. 2013. “American Indian Theater 2013: Not Running on Empty Yet”. The World of Indigenous North America. Ed. R. A. Warrior. New York: Routledge. 330-346

Haugo, A. 2000. “ 'Circles Upon Circles Upon Circles': Native Women in Theater and Performance". American Indian Theater in Performance: A Reader. Eds. H. Geiogamah \& J. T. Darby. Los Angeles: UCLA American Indian Studies Center. 228-255.

Haugo, A. 2013. "Native American Drama: A Historical Survey". Indigenous North American Drama: A Multivocal History. Ed. B. Däwes. Albany: State University of New York. 49-72.

Huntsman, J. F. 2000. "Native American Theatre". American Indian Theater in Performance: A Reader. Ed. H. Geiogamah \& J. T. Darby. Los Angeles: UCLA American Indian Studies Center. 81-103

Kahn, C., Reinschmidt, K., Teufel-Shone, N., Oré de Boehm, Ch., Henson, M. And Attakai, A. 2016. “American Indian Elders' Resilience: Sources of Strength for Building a Healthy Future for Youth". American Indian and Alaska Native Mental Health Research, 23 (3), 117-33. DOI: 10.5820/aian.2303.2016.117.

KING, B. 2000. "Emergence and Discovery: Native American Theater Comes of Age". American Indian Theater in Performance: A Reader. Ed. H. Geiogamah and J. T. Darby. Los Angeles: UCLA American Indian Studies Center. 165-168.

LinCOLn, K. 1993. Indi'n Humor: Bicultural Play in Native America. New York: Oxford University Press.

LóPez PÉREZ, S. 2019. “A Concise Overview of Native American Written Literature: Early Beginnings to 1968". International Journal of Languages, Literature and Linguistics, 5 (3), 176-185.

López Pérez, S. And Benali TaOuis, H. 2016. "Native American Theater: A Concise History". Miscelánea: A Journal of English and American Studies, 54, 93-111.

MoJicA, M. 1991. "Theatrical Diversity on Turtle Island: A Tool Towards the Healing”. Canadian Theatre Review, 68, 3.

Morgan, N., Hornung, A. And Tatsumi, T., eds. 2019. The Routledge Companion to Transnational American Studies. London \& New York: Routledge.

PinAzzI, A. 2000. "The Theater of Hanay Geiogamah". American Indian Theater in Performance: A Reader. Ed. H. Geiogamah \& J. T. Darby. Los Angeles: UCLA American Indian Studies Center. 175-194.

Pulitano, E. 1998. “Telling Stories Through the Stage: A Conversation with William Yellow Robe". Studies in American Indian Literatures, 10 (1), 19-44. 
SCHÄFER, H. 2013. "A Short History of Native Canadian Theatre”. Indigenous North American Drama: A Multivocal History. Ed. B. Däwes. Albany: State University of New York. 29-47.

VASSAR, A. 2007. Geiogamah, Hanay. Encyclopedia of American Indian Literature. Ed. J. McClinton-Temple \& A. Velie. New York: Facts on File. 134-135.

WheELER, J. 1991. “A Revolution in Aboriginal Theatre: Our Own Stories.” Canadian Theatre Review, 8-12.

Wilmeth, D. B., AND Miller T. L., Eds. 1996. The Cambridge Guide to American Theatre. Cambridge: Cambridge University Press.

WeXler, L. 2009. "The Importance of Identity, Culture and History for Indigenous Youth Wellness". The Journal of the History of Childhood and Youth, 2 (2), 267-276. DOI: 10.1353/hcy.0.0055 